\title{
An Empirical Study on Effect of Transformational Leadership On Organizational Commitment In The Banking Sector Of Pakistan
}

\author{
Bano Fakhra Batool \\ Superior university KalmaChowkGulberg Lahore, Punjab Pakistan
}

\begin{abstract}
Transformational leadership is very popular research topic so many researcheshave been done on its every perspective. The objectiveof this paper is to investigate the impact of transformational leadership style a leader exhibits on his subordinate that effects the organizational commitment of his employees in the banking industry of Pakistan.

This research was carried out by measuring the data gathered from the five point Likertscale.The Multifactor Leadership Questionnaire $(M L Q)$ is used to measure transformational leadership and employee's commitment was measured through affective commitment questionnaire of Allen and Meyer (1996). Quantitative survey method was applied and a sample of 100 employees from the banking industry of Pakistan. Random sampling technique is used to answer the instrument of the study. SPSS software was used to analyze the data collected based on descriptive statistics (mean, standard deviation, percentage, T-test, and Pearson Correlation Coeffiecient). The findings indicate that the leaders of bankingindustry of Pakistan follow transformational leadership style. The result indicates that the relationship between transformational leadership style and organizational commitment is positive and significant.
\end{abstract}

Key Words:, attitude, organizational Commitment, Transformational leadership, Pakistan, workplace,

\section{Introduction}

Organizations are doing efforts for long lasting success. Success of an organization depended upon many factors consisting of external and internal factors; work force is considered to be one of the most important contributors of any organizational competitiveness. Capability and ability of an organization to properly utilize the resources give the company a competitive advantage. As a matter of fact human recourse is the major contributing force of utilization of all other resources from the first day of humanity to till this day and till day the this universe is existing. Human recourse, in fact, is the vital asset of the organization. Hiring/recruiting, maintaining and retaining efficient workforce is an important success factor in today's organizations. The objective of any successful organization is not only to hire workforce but also to maintain an efficient and effective labor force. The way the organizations achieved their targets of success human factor plays its role. And the job done by them is possible when they are committed to their task and duties assign to them. So in this regard we can say Human can be committed to their organization when they are guided by their leaders properly when they are motivated by their leaders.

Transformational Leadership is based on the following three assumptions:

subordinates will link together around a person that inspires them;

Leaders with a vision, mission and passion can accomplish extraordinary things;

The way to accomplish great things by the mixture of emotions and encouragement;

It is notreally leading if one does nothing, but it helps to define one's actions which are more critical in today's work environment which is full of competition.The literature indicates that transactions, whether psychological or monetary, must take place between the leader and the follower to produce an observable "leadership process" and that the relationship between leader and constituent must be mutually beneficial (Northouse, 2004). Where there is relationship and sharing of new information, transformational leadership is the method for new energy to do the work" (Warden, 2011, p. 4). Warden's work echoes concepts such as "fractal leadership" or "new science leadership" by Wheatly (1999) and more recently Harle (2011).

On the other hand Organizational commitment is an important factor and has received a significant worth in studies being carried on in different work settings, because it has been considered as a major factor in determining the organizational performance (Ricketta 2002) and effectiveness (Lashinger 2001). Meyer and Allen (1979) have divided Organizational commitment into three basic components- 


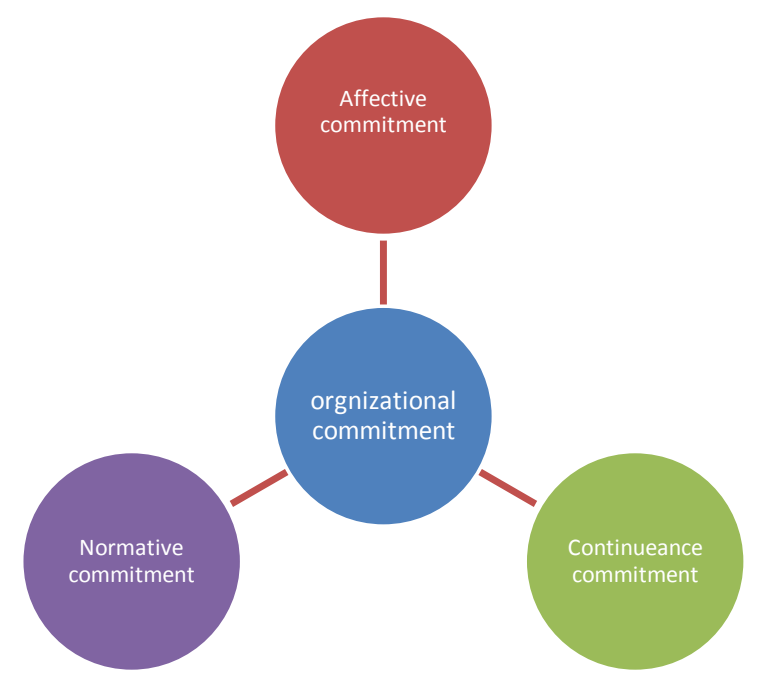

Mentioned above affective commitment is more important for employees when they feel their identification with respect to organization. The degree to which employees show their emotional attachment and affiliation with organization is largely influenced by leadership style a leader apply when dealing with them. Ramchandran and Krishnan (2009) found that there is leader and style of that leader is one of the most important determinants of employee's commitment. Leadership can affect many work related behaviors like, employee's attitude, motivation and performance all of which can affect the levels of organizational commitment (Bass 1985 and Stogdill 1963). Bass (1985) and Stogdills (1963) proposed that there are two main styles of leadership i.e. transformational and transactional. Transactional leaders encourage followers to achieve predictable degree of performance by serving them to be familiar with job responsibilities, recognize goals and build up self-reliance about meeting the desired performance stage (as cited by Chiun et al. 2009). According to Bass and Avolio (1994) there are three components which are occupied by transactional leaders' i.e. management by exception active, management by exception passive and contingent reward. Transformational leaders bring a positive change in those who follow them. They are mostly vigorous, keen, ardent and paying attention on the success of every member of the group. As past research shows that commitment is affected by employees attitude, their work behavior, motivation and performance and transformational leadership is positively linked with all these which enhance the level of commitment both at employees as well as at organizational level (Dumdum et al. 2002).

The aim of this study is to examine the impact of leadership style on employee's organizational commitment. As the study is examining the extent to which employee's affective commitment is influenced by transformational leadership style with respect to Pakistani Banking sector.

\section{Problem Statement}

The banking sector is very important as it is the major contributor of Pakistani economy in services industry and that the interest in this sector is very important. Despite the world global financial crisis and along with the bad economic conditions of the country this sector had produced stable results.

Therefore, this sector needs professional leaders who can achieve maximum goals of both employees and organizations. An organization that is short of capital may resort to borrowing money, and one in a poor location has the option to move. However an organization with short of leadership has little chance for survival (Yousef,1998).

The relationships between organizational commitment and transformational leadership have attracted considerable. Previous researches focused on specific human resource behaviors. Yet not much study has been conducted to investigate the impact transformational leadership style and organizational commitment in particular banking sector of Pakistan. This study, therefore, will help to fill this gap and effort to improve the understanding of the role of leadership in Pakistani banking sector.

\section{Background}

Organizational commitment is an important issue that has been and would always been of great importance for organizations always. Organizations are always looking for the committed human resource in order to achieve its strategic objectives. As noted by Morris and Sherman (1981.) Organizational commitment is a power full and influencing indicator of employee's performance \& turnover. It helps organizations to attain its goals as it is the psychological bond between the individuals and organization (Mowday and McCade 1979). It is the relative strength of an employee's identification with and involvement within an organization (Mowday et al. 1982 and Porter et al. 1974. Effective employee's commitment is the identification and involvement of the 
individuals in achievement of organizational goals (Meyer and Allen 1997).

There are number of factors effecting organizational commitment such as organizational culture, leadership style, job satisfaction, personal characteristics (age, gender, race, job tenure etc.), employees' power, their attitude, work behavior, motivation and performance. One personal and organizational factor that is considered as key antecedent of organizational commitment is leadership (Mowday et al. 1982). Shirbagi (2007) states that there is positive relationship between leadership and overall organizational commitment; he also found positive relationship of leadership style with three components of organizational commitment. (Williams and Hazer 1986) states that Leadership has positive and significant impact on organizational commitment.

As Stogdill (1963) and Bass (1985) proposed two types of leadership style i.e. transformational leadership and transactional leadership styles. Transformational leadership has shown significant and positive relationship with organizational commitment while transactional leadership does not positively and significantly correlates with organizational commitment (Lee 2004). Transformational leaders have great ability to influence organizational commitment by promoting the values which are related to the goal accomplishment, by emphasizing the relation between the employees efforts and goal achievement and by creating a greater degree of personal commitment on part of both follower's as well as leaders for the achievement of ultimate common vision, mission and goals of the organization (Shamir et al. 1998). Transformational leaders motivate subordinates to accomplish more by focusing on their values and provide guidelines for aligning their values with the values of the organization (Givens 2008). Bass (1998) describes that there are further four facets of transformational leadership

Table 1. Dimensions of Transformational Leaders (Bass \&Avolio, 1990)

\begin{tabular}{|l|l|}
\hline Idealized Influence (II) & $\begin{array}{l}\text { Making others feel good, making others proud, earning faith from } \\
\text { the subordinate }\end{array}$ \\
\hline Inspirational Motivation (IM) & $\begin{array}{l}\text { Leader communicates his/her goals, the manipulation of images, } \\
\text { helping others find meaning in their work }\end{array}$ \\
\hline Intellectual Stimulation (IS) & $\begin{array}{l}\text { Leader's ability to make others think about new ways to perform } \\
\text { work, new ways to look at work, ways to be creative in their own } \\
\text { problem-solving methods }\end{array}$ \\
\hline Individual Consideration (IC) & $\begin{array}{l}\text { Individuals develop themselves, leader feedback to subordinates, } \\
\text { time taken by the leader to bring workers into the team or group }\end{array}$ \\
\hline
\end{tabular}

\section{Idealized Influence (II)}

According to Bass (1990), Idealized Influence is the dimension characterized by making others feel good, making others proud to be associated with the leader, and earning faith from the subordinate.

\section{Inspirational Motivation (IM)}

Bass (1990) noted that this dimension is characterized by how well the leader communicates his or her goals, the manipulation of images, and helping others find meaning in their work.

\section{Intellectual Stimulation (IS)}

Bass (1990) noted that this dimension is characterized by the leader's ability to make others think about new ways of performing work, new ways of looking at work, and to be creative in their own problem-solving methods.

\section{Individual Consideration (IC)}

Bass (1990) noted that this dimension is characterized by how well the leader encourages individuals to develop themselves, how much feedback the leader thinks he or she gives to subordinates, and how well the leader takes the time to bring workers into the team or the group.

"people are machines" model as well as the "people are entirely dependent on the leader" model (Warden, 2011). Northouse (2004) noted that the strengths of the TL model are that it allows for multiple perspectives, it is intuitive, and it is process-based Another strength is that the process seems intuitive to the leader because of the focus on the follower's needs.

All these findings are given in different work setting considering many other factors as well. Like, Davenport (2010) found that personality type and Leadership style both are important predictors of organizational commitment. He found that employees with internal locus of control are more committed towards organization/s; similarly employees who follow transformational leaders are also more committed towards their organizations. Similarly Shukui and Xiaomin (2009) found that transformational leadership has positive 
relationship with employees' commitment but when organizational culture operates between transformational leadership does not positively influence the organizational commitment. Mert et al. (2010) states that transformational leadership style positively effect organizational commitment of followers. Similar findings were given by Tseng and Kang (2008) when they found that there is positive and significant relationship between transformational leadership style and organizational commitment. Charisma, intellectual stimulation and individualize consideration factors of transformational leadership are more significantly related with organizational commitment and job satisfaction (Emery and Barker 2007). Transformational leadership is positively correlated with the organizational commitment (Avolio et al. 2004). Chiun et al. (2009) states that Different angles of transformational leadership have positive relationship with organizational commitment. Jean Lee et al., (2004) conducted research to find out effects of leadership style on organizational commitment; there results revealed that transformational style of leaders has direct bearing on commitment level of employees.

When considering impact of transformational leadership style on the facets of organizational commitment (Normative, Continuance and Affective Commitment) very little literature is available on the specific issue. Ekeland (2005) found that transformational leadership has positive effect on follower's affective commitment. Transformational leadership has a positive effect on followers' affective andUnfortunately, in real life of the organization that is what people don't do-they use their natural or by default style used in most situations. Leadership can be defined as establishing a clear vision, communicating the vision with others and resolving the conflicts between various individuals who are responsible for completing the organization's vision.

\section{Methodology}

Banking sector was taken for the this study because of regular interaction between managers (Leaders) and employees in it, so there would be a direct impact/effect of managers transformational leadership style on the behaviors and actions of the employees. Population of this study is the banking employees. Questionnaire was used as a tool of data collection. Using simple random sampling technique. 100 questionnaires were distributed in those branches/banks and 95 questionnaires were received back with a response rate of $93 \%$.

\section{Instrumentation}

The transformational leadership was measured through multifactor's leadership questionnaires (MLQ) designed by Bass and Avolio (1997) consisting of 17 items. Four facets of transformational leadership were used in MLQ; individualized consideration, inspirational motivation, idealized influence and intellectual stimulation. 5 items for individualize consideration, 4 items for idealized influence, 4 items for inspirational motivation and 4 items for intellectual stimulation were used. Five point likert scales ranging from 1 for never, 2 for seldom, 3 for sometime, 4 for often and 5 for always was used for that purpose. Orgnaizationalemployee's commitment was measured through affective commitment questionnaire of Allen and Meyer (1996) consisting of 6 items. Five point likert scale was used ranging from (strongly disagree $=1$ to strongly agree $=5$ ). The overall cronbach's alpha (both of affective employees' commitment and transformational leadership) was amounted to 0.802. Data Analysis Data collected through questionnaire was analyzed by using SPSS 20.0

\section{Data Analysis}

Findings of the study are given below

This table reveals information regarding Age, gender, qualification, and work experience. Table shows that majority of the respondents (48\%) belong to the young age bracket (25-35), $20 \%$ belong to age bracket of $36-40$ years, $28 \%$ belong to age bracket of 41-50 years of age and only $4 \%$ of the respondents belong to the age group of above 50. This table also shows respondents division according to gender, it shows that majority of the respondents (56\%) are male and only (44\%) are female respondents

\section{Age * Gender Cross tabulation}

\begin{tabular}{|c|c|c|c|c|c|}
\hline & & & Ger & & Total \\
\hline & & & female & male & \\
\hline & & Count & 16 & 30 & 46 \\
\hline & & $\%$ within Age & $34.8 \%$ & $65.2 \%$ & $100.0 \%$ \\
\hline & $36-40$ & Count & & 20 & \\
\hline Age & & $\%$ within Age & $0.0 \%$ & $100.0 \%$ & $100.0 \%$ \\
\hline & $41-50$ & Count & $\begin{array}{r}12 \\
\end{array}$ & $\begin{array}{r}16 \\
-\end{array}$ & 28 \\
\hline & & Count & 2 & 4 & 6 \\
\hline & נובנ & $\%$ within Age & $33.3 \%$ & $66.7 \%$ & $100.0 \%$ \\
\hline
\end{tabular}




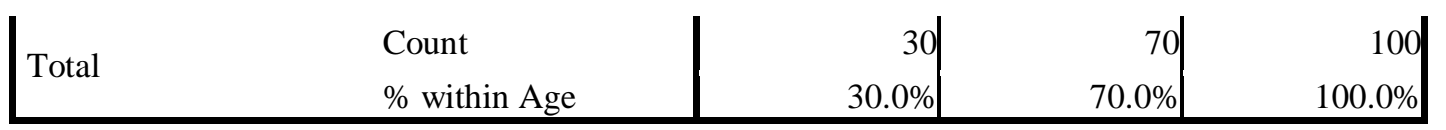

When respondents are divided according to their qualification, table shows that majority of the respondents were holding masters degree $(51 \%)$, only $36 \%$ of the respondents belong to the group having bachelors degree, similarly only $11 \%$ of the respondents were holding degree above masters, very few of them were having no degree and hold only certificates.

Qualification * Gender Cross tabulation

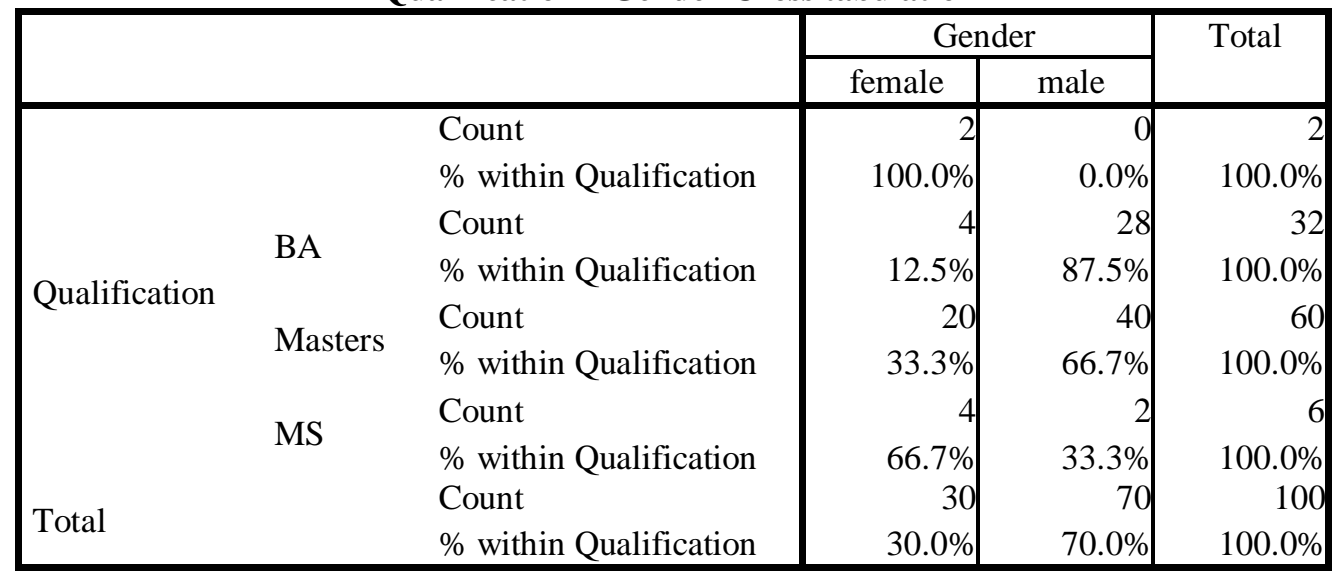

When respondents were inquired about their work experience $(55 \%)$ of the respondents were having work experience between 5 -10 years, employees having 10-15 years of work experience were $28 \%$ between 15-20 years were $(17 \%)$.

Experience * Gender Cross tabulation

\begin{tabular}{|c|c|c|c|c|c|}
\hline & \multicolumn{2}{|c|}{ Gender } & \multirow[t]{2}{*}{ Total } \\
\hline & & & female & male & \\
\hline \multirow{6}{*}{ Experience } & \multirow{2}{*}{$5-10$} & Count & 18 & 42 & 60 \\
\hline & & $\%$ within Experience & $30.0 \%$ & $70.0 \%$ & $100.0 \%$ \\
\hline & \multirow{2}{*}{$10-15$} & Count & 2 & 24 & 26 \\
\hline & & $\%$ within Experience & $7.7 \%$ & $92.3 \%$ & $100.0 \%$ \\
\hline & \multirow{2}{*}{$15-20$} & Count & 10 & 4 & 14 \\
\hline & & $\%$ within Experience & $71.4 \%$ & $28.6 \%$ & $100.0 \%$ \\
\hline \multirow{2}{*}{ Total } & & Count & 30 & 70 & 100 \\
\hline & & $\%$ within Experience & $30.0 \%$ & $70.0 \%$ & $100.0 \%$ \\
\hline
\end{tabular}

When respondents were inquired about their Job title it was reveal $20 \%$ were operations manager $17 \%$ manager $18 \%$ IT officer $10 \%$ Operations officer $14 \%$ cash officer $14 \%$ CAD Officer $4 \%$ and remaining $14 \%$ Credit manager.

Occupation * Gender Crosstabulation

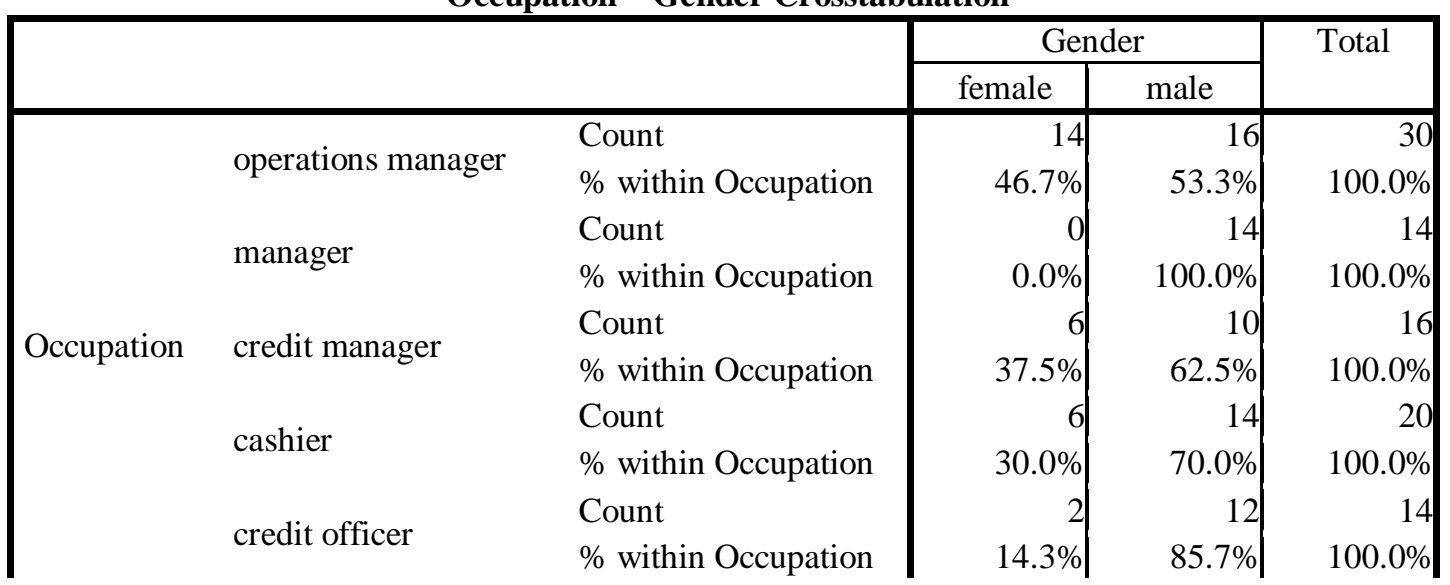




\begin{tabular}{|ll|r|r|r|}
\hline & IT officer & Count & 2 & 4 \\
& \% within Occupation & $33.3 \%$ & $66.7 \%$ & $100.0 \%$ \\
Total & Count & 30 & 70 & 100 \\
\hline
\end{tabular}

Results in Table 2 show the model summary of regression analysis of Independent variables and dependent variable. $\mathrm{R}$ value of the table shows the Correlation coefficient ( $\mathrm{r}$ ) of the analysis $(\mathrm{r}=.543)$, it show that there is strong and positive relationship between transformational leadership and affective commitment. R2 shows the change in dependent variable due to independent variable, value shows in table $(\mathrm{R} 2=.295)$ which shows that that $29.5 \%$ of the change in dependent variable is due to independent variable and rest can be attributed to other factors.

Model Summary

\begin{tabular}{|l|r|r|r|r|}
\hline Model & R & R Square & \multicolumn{1}{|c|}{$\begin{array}{c}\text { Adjusted R } \\
\text { Square }\end{array}$} & $\begin{array}{c}\text { Std. Error of the } \\
\text { Estimate }\end{array}$ \\
\hline 1 & $.543^{2}$ & .295 & .002 & .623 \\
\hline
\end{tabular}

a. Predictors: (Constant), Laissez-faire Leadership, Idealized

Influence, Inspirational Motivation , Management-by-exception ,

Contingent Reward, Individualized Consideration, Intellectual

Stimulation

\begin{tabular}{|ll|r|r|r|r|r|}
\hline \multicolumn{1}{|c|}{ Model } & Sum of Squares & df & Mean Square & F & Sig. \\
\hline \multirow{4}{*}{1} & Regression & 1.099 & 4 & .275 & 1.577 & $.187^{\mathrm{a}}$ \\
& Residual & 15.859 & 91 & .174 & & \\
& Total & 16.958 & 95 & & & \\
\hline
\end{tabular}

a. Dependent Variable: Affective commitment

b. Predictors: (Constant), Individualized Consideration , Intellectual Stimulation , Idealized

Influence, Inspirational Motivation

Coefficients $^{\mathrm{a}}$

\begin{tabular}{|c|c|c|c|c|c|c|}
\hline \multirow[t]{2}{*}{ Mod } & & \multicolumn{2}{|c|}{ Unstandardized Coefficients } & \multirow{2}{*}{$\begin{array}{l}\text { Standardized } \\
\text { Coefficients } \\
\text { Beta }\end{array}$} & \multirow[t]{2}{*}{$\mathrm{t}$} & \multirow[t]{2}{*}{ Sig. } \\
\hline & & B & Std. Error & & & \\
\hline \multirow{5}{*}{1} & (Constant) & 1.238 & .370 & & 3.351 & .001 \\
\hline & Idealized Influence & -.148 & .100 & -.168 & -1.472 & 144 \\
\hline & Inspirational Motivation & .107 & .100 & .126 & 1.070 & 287 \\
\hline & Intellectual Stimulation & -.035 & .100 & -.041 & -.346 & .730 \\
\hline & $\begin{array}{l}\text { Individualized } \\
\text { Consideration }\end{array}$ & .067 & .101 & .075 & 663 & .509 \\
\hline
\end{tabular}

a. Dependent Variable: Affective commitment

Results in Table 3 show the significance of relationship between Independent variables and dependent variables. It shows (Unstandardized Coefficients Beta) value that if there is one unit change in Independent variable what would be unit change in dependent variable, the results show that if one there is one unit change in Independent variable (Transformational Leadership) there would be .70 change in dependent variable (affective commitment). It also shows that there is there is significant relationship between transformation leadership and employees commitment $(\mathrm{p}=.000<.05)$

\section{Discussion}

Findings show that there is significant relationship between leadership style and Organizational commitment it also indicate that Transformational leadership style strongly effect employees' commitment towards their organization. It also shows the independent affects of all dimensions of Transformational leadership which also prove that there is significant and positive relationship between transformational leadership and employees' affective commitment.

\section{LIMITATIONS AND FUTURE IMPLEMENTATION OF THE STUDY}

Findings of the study reveal that transformational leadership style brings positive changes in the behaviors of employees. In the presence of leader with transformational leadership style there would be higher level of employee commitment. So this study in itself can be used in organizations to increase commitment level 
of employees. But in order to generalize the results of the study this study should be conducted in various cities, different culture and in various parts of the country at different organizational levels; as this study is conducted on four banks and only one city was selected for study. Similarly the sample size of the study is very small which should be increased in order to increase generalizbility of the study. This study can further be enhanced by considering other dimensions/facets of commitment i.e. normative and continuance commitment and other leadership styles. This study can also further hit upon in non-financial organizations in Pakistan.

\section{Conclusion}

This study has evaluated the effect of leadership styles on organizational Commitment in National Bank Of Pakistan. The analysis has shown that each of charisma and intellectual stimulation/individual consideration traits of transformational leadership style exerts positive impact on the performance of employees and leading to the strong commitment for their organization. The other trait, inspirational motivation, exerts negative but insignificant effect on performance, and. On the other hand, each trait of transactional leadership style considered in this study, constructive/contingent reward and corrective and management by exception has significant positive effect on followers and performance, and both jointly explain very high proportion of variations in performance. The study concludes that transformational leadership style is more appropriate in inducing performance in NBP than transactional leadership style. Consequently, the study recommends that National Bank of Pakistan should adopt transformational leadership

The need for leaders to fully understand the competencies necessary to become a successful transformational leader is becoming increasingly important due to the rapid changes and innovations in today's market. From the research discussed in this study, we can clearly see the positive outcomes of transformational leadership.

\section{References:}

[1] Avolio, B. J., \& Bass, B. M. (2004).Multifactor leadership questionnaire: manual and sampler set. Mind Garden,Inc.

[2] Avolio, B. J., \&Yammarino, F. J. (2002).Transformational and charismatic leadership: The road ahead. NewYork: Erlbaum.

[3] Bass, B. M. (1985). Leadership and performance beyond expectations. Free Press.

[4] Bass, B. M., Avolio, B. J., Jung, D. I., \&Berson, Y. (2003). Predicting unit performance by assessingtransformational and transactional leadership. Journal of applied psychology, 88(2), 207.

[5] Al-Sharifi, A. M., \& Al-Tanah, M. M. (2010). The degree of practicing transformational leadership by privatesecondary school principals in the UAE. Journal of Human Sciences, 45(7), 1-28.

[6] Allen NJ, Meyer JP (1996) Affective, continuance and normative commitment to the organization: An examination of construct validity. Journal of Vocational Behavior. 49: 252-276.

[7] Avolio B. J, Zhu. W, Koh. W and Bhatia. P (2004) Transformational Leadership and Organizational Commitment: Mediating Role of Psychological Empowerment and Moderating Role of Structural Distance, Journal of Organizational Behavior, 25, $951-968$.

[8] www.sagepub.com/northouseintro2e,www.FlexibleTrainingPartners.com

[9] www.northsomerset.nhs.uk/.../leadership\%20styles\%20question

[10] www.ajbmr.com/articlepdf/ajbmr_17_16i1n7a11.pdf

[11] Allen NJ, Meyer JP (1996) Affective, continuance and normative commitment to the organization: An examination of construct validity. Journal of Vocational Behavior. 49: 252-276.

[12] Avolio B. J, Zhu. W, Koh. W and Bhatia. P (2004) Transformational Leadership andorganizational commitmentAvolio BJ (1999). Full leadership development. Thousand Oaks. CA: Sage.

[13] Avolio BJ, Bass BM, Jung DI (1995). Construct validation and norms for the multifactor leadership questionnaire (MLQ-Form 5X). New York Center for leadership studies.Binghamton University.State University of New York.

[14] Avolio BJ, Bass BM, Jung DI (1999). Re-examining the components of transformational and transactional leadership using the Multifactor Leadership Questionnaire.Journal of Occupational and Organizational Psychology. 72: 441-462.

Bass BM (1985). Leadership and performance beyond expectations.New York Free Press.

[16] Bass BM (1998). Transformational leadership: Industry, military, and educational impact. Mahwah.NJ Erlbaum.

[17] Bass BM (1999). Two decades of research and development in transformational leadership. European Journal of Work and Organizational Psychology. 8(1): 9-32.

[18] Bass BM, Avolio BJ (1990). The implications of transactional and transformational leadership for individual, team, and organizational development.Research in Organizational Change and Development. 4: 231-272.

[19] Bass BM, Avolio BJ (1993). Transformational leadership and organizational culture. Public Xenikou, A., \&Simosi, M. (2006). Organizational culture and transformational leadership as predictors ofbusiness unit performance. Journal of Managerial Psychology, 21(6), 566-579.

[20] http://dx.doi.org/10.1108/02683940610684409

[21] Administration Quarterly. 17: 112-121. 